\title{
Pengaruh Model Project-Based Learning Berbasis Alat Peraga Terhadap Kemampuan Berpikir Kritis Siswa Kelas VII MTS Raudhatul Thalabah
}

\author{
1Zulfa Husniatul Islamiyah, ${ }^{2}$ Windra Eka Lestari \\ ${ }^{12}$ Tadris Matematika, Tarbiyah dan Ilmu Keguruan, IAIN Tulungagung \\ Jl. Mayor sujadi timur No. 46 Tulungagung \\ Email: ${ }^{\text {zulfahusnia96@gmail.com, }{ }^{2} \text { lestariwindra87@gmail.com }}$
}

\section{Article History:}

Received: 15-09-2018; Received in revised form: 09-10-2018; Accepted: 28-12-2018;

Available online: $30-12-2018$

\begin{abstract}
The purpose of this research was to know the influence of Project-Based Learning models by Props toward critical thinking of the seventh grade students in Mathematic learning. The design of the study was true-experimental research design with non-equivalent post-test only control group design. On the experimental group it was applied Project-Based Learning model, where as in the control group it was applied a conventional learning model. The data were collected through documentations as written test. This study concluded that students who follow the cooperative project-based learning are more critical thinking better learning outcomes than the other class who follow the direct instruction strategy. So, there is the influence of Project-Based Learning models by props toward critical thingking ability of the seventh grade students at MTs Raudhatul Thalabah.
\end{abstract}

Keywords: Project-Based Learning; Props; Critical Thinking Ability

Abstrak

Penelitian ini bertujuan untuk mengetahui pengaruh model Project-Based Learning berbasis alat peraga terhadap kemampuan berpikir kritis siswa pada pembelajaran Matematika. Jenis penelitian ini adalah penelitian true-experiment dengan rancangan non-equivalent post-test only control group design. Pada kelompok eksperimen diterapkan model pembelajaran berbasis proyek, sedangkan pada kelompok kontrol diterapkan model pembelajaran konvensional. Data dikumpulkan menggunakan dokumentasi berupa tes tulis. Hasil penelitian ini menunjukkan bahwa kemampuan berpikir kritis siswa yang mengikuti cooperative ProjectBased Learning lebih baik dibandingkan siswa yang mengikuti pembelajaran langsung seperti yang dilaksanakan selama ini. Dengan kata lain ada pengaruh model pembelajaran ProjectBased Learning berbasis alat peraga terhadap kemampuan berpikir kritis siswa kelas VII MTs Raudhatul Thalabah.

Kata Kunci: Project-Based Learning; Alat Peraga; Kemampuan Berpikir Kritis 


\section{Pendahuluan}

Pendidikan adalah usaha sadar yang dilakukan pemerintah, melalui kegiatan bimbingan, pengajaran, dan/ atau latihan, yang berlangsung di sekolah dan di luar sekolah sepanjang hayat, untuk mempersiapkan siswa agar dapat memainkan peranan dalam berbagai lingkungan hidup secara tepat di masa yang akan datang ${ }^{1}$. Pendidikan ini menjadi kegiatan yang terprogram baik dalam bentuk pendidikan formal, non formal maupun informal. Pendidikan berguna bagi siswa dalam menghadapi kehidupan di masa yang akan datang. Mereka akan dituntut menjadi pekerja yang profesional di bidangnya masing-masing.

Pendidikan di Indonesia masih tergolong sangat rendah meski telah mengalami peningkatan dari tahun-tahun sebelumnya. Hasil PISA (Program for International Student Assessment) pada tahun 2015 dan dirilis 6 Desember 2016, dari 72 negara yang di survei, Indonesia menempati peringkat 64 mengenai skor pencapaian siswa untuk bidang Matematika, Sains, dan membaca ${ }^{2}$. Hal ini menunjukkan bahwa Indonesia berada pada kelompok negara dengan penguasaan materi yang rendah.

Pada penerapannya di sekolah, model pembelajaran matematika yang diterapkan cenderung berorientasi pada pengembangan pemikiran analitis dengan masalah-masalah yang rutin. Model pembelajaran yang berorientasi pada upaya pengembangan penguasaan materi masih jarang ditemukan. Guru di sekolah lebih mengajarkan matematika secara hafalan melalui konsep matematika yang sudah ada, tanpa memperhatikan siswa memahami konsep tersebut dengan baik atau belum. Padahal pemahaman siswa akan konsep ini yang perlu ditekankan untuk mengembangkan kemampuan berpikir kritisnya. Oleh karena itu, guru hendaknya mampu menciptakan suasana belajar yang memungkinkan bagi siswa untuk mengkonstruksi, menemukan, dan mengembangkan kemampuannya hingga siswa dapat belajar sendiri sesuai dengan keinginannya. Salah satu langkah yang bisa dilakukan oleh guru sebagai pembimbing siswa adalah memilih model pembelajaran yang tepat.

Pembelajaran aktif merupakan salah satu model pembelajaran yang menuntut siswa untuk berperan aktif dalam proses pembelajaran, sehingga siswa diharapkan dapat mengoptimalkan potensi yang dimilikinya ${ }^{3}$.

\footnotetext{
${ }^{1}$ Binti Maunah, Landasan Pendidikan (Yogyakarta: Teras, 2009).

2 "Peringkat Dan Capaian PISA Indonesia Mengalami Peningkatan," Kementerian Pendidikan dan Kebudayaan, December 2016, https:/www.kemdikbud.go.id/main/blog/2016/12/peringkat-dan-capaian-pisa-indonesiamengalami-peningkatan.

${ }^{3}$ Muhammad Kharis Kurniawan et al., "Penerapan Pembelajaran Aktif Berbasis Tugas Proyek untuk Meningkatkan Hasil Belajar IPA Siswa Kelas VII B SMP Kristen 2 Salatiga Tahun Pelajaran 2016/2017 Active Learning Application Based on Project Assignment in Improving
} 
Pembelajaran aktif pada dasarnya berusaha untuk memperkuat stimulus dan respon siswa dalam pembelajaran, sehingga pembelajaran menjadi hal yang menyenangkan dan tidak menjadi hal yang membosankan bagi siswa. Penekanan proses pembelajaran bukan pada penyampaian informasi oleh pengajar, melainkan pada pengembangan keterampilan pemikiran analitis dan kritis terhadap topik atau permasalahan yang dibahas, eksplorasi nilainilai dan sikap-sikap yang berkenaan dengan materi pelajaran.

Pembelajaran berbasis proyek merupakan salah satu metode pembelajaran yang menekankan pada pemberian kesempatan kepada siswa untuk menghasilkan suatu karya melalui pengembangan pengetahuan, sikap, nilai dan keterampilan sosial yang berguna bagi kehidupannya di masyarakat. Karya yang dihasilkan dapat berupa suatu rancangan, model, produk yang nyata yang dapat diterapkan di masyarakat.

Pembelajaran berbasis proyek memiliki potensi yang amat besar untuk membuat pengalaman belajar yang lebih menarik untuk pelajar ${ }^{4}$. Di dalam pembelajaran berbasis proyek, pelajar menjadi terdorong lebih aktif di dalam belajar mereka, guru sebagai fasilitator agar siswa lebih kreatif dan lebih aktif. Selain itu, guru juga bertugas mengevaluasi hasil kerja siswa agar lebih efektif penerapannya untuk kehidupan mereka sehari-hari.

Begitu pentingnya pembelajaran yang melibatkan seluruh indra dan pikiran. Oleh karenanya hal ini akan menjadikan proses pembelajaran dengan pendapatan pengalaman baik secara langsung maupun tak langsung. Sehingga, keterlibatan indra dan pikiran dalam pembelajaran adalah suatu hal yang mutlak ada. Firman Allah QS. Yunus ayat 101 yang berbunyi:

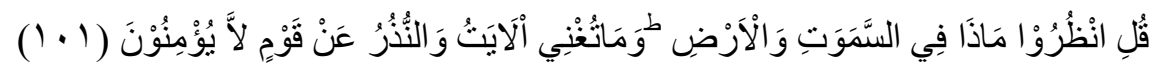

Artinya: Katakanlah, "Perhatikanlah apa yang ada di langit dan di Bumi!" tidaklah bermanfaat tanda-tanda (kebesaran Allah) dan rasul-rasul yang memberi peringatan bagi orang yang tidak beriman.

Pada ayat tersebut, telah jelas memberikan penjelasan kepada manusia untuk memperhatikan segala apa yang ada di bumi dengan menggunakan indra dan pikirannya. Sebab dengan menggunakan alat indra, akan memberikan pelajaran kepada orang yang mendengarnya untuk selalu berfikir dan mengoptimalkan penggunaan akal pikirannya.

Berdasarkan penelitian yang dilakukan Dewi Insyasiska, Siti Zubaidah, dan Herawati Susilo, hasil uji hipotesis menujukkan bahwa terdapat

Science Learning Results of Stu," Bioedukasi: Jurnal Pendidikan Biologi 10, no. 1 (February 15, 2017): 33-42, https://doi.org/10.20961/bioedukasi-uns.v10i1.10140.

${ }^{4}$ Warda Murti, "Pengaruh Pemberian Tugas Berbasis Proyek Terhadap Pengembangan Life Skill Dan Hasil Belajar Biologi Siswa Kelas VIII SMP,” Jurnal Biotek 4, no. 1 (June 1, 2016): 21-32, https://doi.org/10.24252/jb.v4i1.1767. 
pengaruh pembelajaran berbasis proyek terhadap motivasi belajar, kreativitas, kemampuan berpikir kritis, dan kemampuan kognitif siswa ${ }^{5}$. Dapat disimpulkan dalam penelitian yang di lakukan bahwa model pembelajaran Project Based Learning sangat berpengaruh bagi kemampuan berpikir siswa dalam pembelajaran.

Alasan memberikan tugas berbasis proyek kepada siswa ini untuk mengembangkan keterampilan yang ada dalam dirinya. Selain itu, dengan memberikan tugas berbasis proyek ini dapat mengetahui kemampuan berpikir kritis siswa dalam belajar serta meningkatkan hasil belajar siswa yang mencakup tiga ranah yaitu kognitif, afektif dan psikomotorik. Dengan alasan tersebut maka dipandang penting untuk mengadakan penelitian tentang Pengaruh Model Project Based-Learning Berbasis Alat Peraga terhadap Kemampuan Berpikir Kritis Siswa Kelas VII.

\section{Metode}

Penelitian ini menggunakan true-experiments karena dalam desain ini peneliti dapat mengontrol semua variabel luar yang mempengaruhi jalannya eksperimen. Jadi, validitas internal (kualitas pelaksanaan rancangan penelitian) menjadi tinggi. Tujuan dari true experiments adalah untuk menyelidiki kemungkinan saling hubungan sebab akibat dengan cara mengenakan perlakuan dan membandingkan hasilnya dengan grup kontrol yang tidak diberi perlakuan. True experiments ini mempunyai ciri utama yaitu sampel yang digunakan untuk eksperimen maupun sebagai kelompok kontrol diambil secara random dari populasi tertentu.

Dalam desain ini terdapat dua kelompok yang masing-masing dipilih secara random (R). Grup pertama diberi perlakuan $(\mathrm{X})$ dan grup yang lain tidak.

Bagan penelitian ini adalah sebagai berikut:

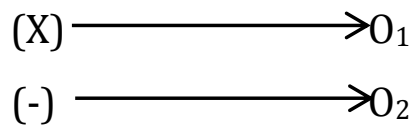

Dalam penelitian, pengaruh perlakuan dianalisis dengan uji beda menggunakan statistik t-test. Jika ada perbedaan yang signifikan antara grup eksperimen dan grup kontrol, maka perlakuan yang diberikan berpengaruh secara signifikan.

Populasi penelitian ini adalah siswa kelas VII MTs Raudhatul Thalabah tahun pelajaran 2018/2019. Pengambilan sampel dilakukan dengan teknik simple random sampling, diambil 2 kelas, satu kelas sebagai kelas eksperimen, dan satu kelas kontrol. Kelas eksperimen yaitu VII-A terdiri dari

\footnotetext{
${ }^{5}$ Dewi Insyasiska, Siti Zubaidah, and Herawati Susilo, "Pengaruh Project Based Learning Terhadap Motivasi Belajar, Kreativitas, Kemampuan Berpikir Kritis, Dan Kemampuan Kognitif Siswa Pada Pembelajaran Biologi," Jurnal Pendidikan Biologi 7, no. 1 (April 5, 2017): 9-21.
} 
30 siswa yang diperlakukan dengan pembelajaran berbasis proyek, sedangkan kelas kontrol yaitu VII-B terdiri dari 30 siswa yang diberikan pembelajaran konvensional. Sampel yang digunakan berjumlah 60 siswa.

Variabel bebas dalam penelitian ini adalah Project-Based Learning berbasis alat peraga. Variabel terikat dalam penelitian ini adalah kemampuan berpikir kritis siswa kelas VII MTs Raudhatul Thalabah. Variabel kontrol dalam penelitian ini adalah materi pembelajaran Matematika kelas VII semester 2 kompetensi dasar Segitiga dan Segiempat.

Instrumen penelitian yang digunakan dalam penelitian ini terdiri atas:

1. Perangkat pembelajaran (RPP dan LKS)

2. Instrumen keterlaksanaan pembelajaran proyek untuk mengontrol proses pembelajaran berlangsung dilakukan observasi dengan menggunakan rubrik observasi keterlaksanaan pembelajaran

3. Test kemampuan berpikir kritis dan penilaian produk sebagai hasil dari proyek menggunakan rubrik.

Data diambil selama pembelajaran proyek, yang berlangsung selama $2 \mathrm{x}$ 40 menit dengan materi Segitiga dan Segiempat. Data yang digunakan dalam penelitian ini adalah data nilai test, yang diperoleh melalui posttest dari kelas eksperimen dan kelas kontrol. Data posttest berupa nilai kemampuan berpikir kritis setelah diberi perlakuan model Project-Based Learning di kelas eksperimen dan model pembelajaran konvensional di kelas kontrol.

Analisis data menggunakan analisis statistik uji beda atau uji-t. Sebelum uji hipotesis, dilakukan uji prasyarat normalitas dan homogenitas data. Uji normalitas menggunakan uji One Sample Kolmogorov-Smirnov, sedangkan uji homogenitas menggunakan Test of Homogeneity of Variances yang dibantu dengan program SPSS 16 for Windows. Pengujian statistik dilakukan pada taraf signifikansi $0.5 \%$.

\section{Hasil Analisis Statistik Deskriptif}

Pengumpulan data kemampuan berpikir kritis siswa pada pokok bahasan Segitiga dan Segiempat untuk kelas eksperimen, menggunakan model pembelajaran Project-Based Learning dan pada kelas kontrol, diterapkan model pembelajaran konvensional. yang dilakukan melalui tes tulis berupa soal-soal yang dikerjakan oleh siswa. Data hasil kemampuan berpikir kritis siswa dapat dilihat di tabel berikut: 
Tabel. 1 Deskripsi Kemampuan Berpikir Kritis Siswa Setelah Perlakuan

\begin{tabular}{l|c|c}
\hline \multicolumn{1}{c|}{ Statistik } & Kelas Eksperimen & Kelas Kontrol \\
\hline Nilai terendah & 30 & 30 \\
\hline Nilai tertinggi & 100 & 100 \\
\hline Rata-rata & 70,67 & 62,67 \\
\hline Modus & 80 & 40 \\
\hline
\end{tabular}

Berdasarkan tabel di atas, dapat dinyatakan bahwa siswa yang belajar dengan model pembelajaran Project-Based Learning lebih baik dari siswa yang belajar dengan model pembelajaran konvensional.

\section{Hasil Analisis Statistik Inferensial}

Sebagai persyaratan analisis, terlebih dahulu dilakukan uji normalitas dan Uji Homogenitas.

\section{Uji Normalitas}

Uji normalitas data kemampuan berpikir kritis siswa dilakukan dengan menggunakan uji Kolmogorov-Smirnov. Perhitungan uji normalitas Kolmogorov-Smirnov dari data hasil post-test kemampuan berpikir kritis siswa dengan berbantuan program SPSS sebagai berikut :

Tabel. 2 Hasil Uji Normalitas

\begin{tabular}{l|c|r|r|r}
\hline & \multirow{2}{*}{ Faktor } & \multicolumn{3}{|c}{ Kolmogorov-Smirnov $^{\mathrm{a}}$} \\
\cline { 3 - 5 } & & Statistic & df & \multicolumn{1}{c}{ Sig. } \\
\hline Kemampuan Berpikir & Eksperimen & 0,195 & 30 & 0,005 \\
\cline { 2 - 5 } Kritis & Kontrol & 0,139 & 30 & 0,146 \\
\hline
\end{tabular}

a. Lilliefors Significance Correction

Berdasarkan hasil uji normalitas data hasil post-test kemampuan berpikir kritis siswa di atas, dapat disimpulkan bahwa data tersebut berdistribusi normal.

\section{Uji Homogenitas}

Uji homogenitas data kemampuan berpikir kritis siswa dianalisis dengan menggunakan SPSS

Tabel. 3 Hasil Uji Homogenitas

\begin{tabular}{lr|r|r|rr}
\hline \multicolumn{2}{l|}{ Levene Statistic } & \multicolumn{1}{c|}{ df1 } & df2 & \multicolumn{2}{c}{ Sig. } \\
\hline & 1,103 & 1 & 58 & & 0,298
\end{tabular}


Tabel 4. ANOVA Kemampuan Berpikir Kritis

\begin{tabular}{c|r|r|r|c|c}
\hline & $\begin{array}{c}\text { Sum of } \\
\text { Squares }\end{array}$ & df & $\begin{array}{c}\text { Mean } \\
\text { Square }\end{array}$ & F & Sig. \\
\hline Between Groups & 960 & 1 & 960 & 2,144 & 0,149 \\
\hline Within Groups & 25973,33 & 58 & 447,816 & & \\
\hline Total & 26933,33 & 59 & & & \\
\hline
\end{tabular}

Berdasarkan Tabel 4 menunjukkan bahwa hasil signifikansi dari uji homogenitas adalah 0,298. Jadi dapat diambil kesimpulan bahwa $\mathrm{H}_{0}$ ditolak, sehingga data tersebut bersifat homogen.

\section{Deskripsi Kemampuan Berpikir Siswa}

Penelitian dilaksanakan pada dua kelompok sampel, yaitu kelompok eksperimen dan kelompok kontrol dengan non-equivalent control group design. Data yang diperoleh meliputi data posttest terhadap kemampuan berpikir kritis. Pembelajaran dilakukan sebanyak 1 kali pertemuan. Setiap kelas diberi materi, jam praktik, suasana dan kondisi yang sama namun menggunakan strategi pembelajaran yang berbeda sesuai rancangan penelitian. Materi yang dipelajari adalah Segitiga dan Segiempat. Pembelajaran pada kelas eksperimen menerapkan Project-Based Learning, sedangkan kelas kontrol menggunakan pembelajaran konvensional. Masingmasing pertemuan berdurasi 2 × 40 menit.

Hasil observasi menyatakan bahwa pembelajaran dapat terlaksana sesuai dengan yang direncanakan, meskipun terdapat kendala pada perlakuan 1 untuk kelas eksperimen, yaitu terdapat sebagian siswa belum memberi umpan balik pada akhir pembelajaran karena keterbatasan waktu. Namun, kendala ini dapat teratasi pada perlakuan 2 dengan membatasi waktu menjawab bagi siswa sehingga partisipasi siswa meningkat. Dilihat dari pelaksanaan pembelajaran pada kelas kontrol, RPP yang direncanakan dapat berjalan dengan baik. Selain itu, dilihat dari keseriusan guru saat mengajar, observer menyatakan bahwa guru cukup serius mengajar baik mengajar di kelas eksperimen maupun kelas kontrol. Guru melaksanakan pembelajaran sesuai dengan RPP serta melaksanakan tahapan pembelajaran termasuk mengontrol waktu setiap tahapannya. Deskripsi data akhir setelah diberikan perlakuan dilakukan pengambilan data kemampuan berpikir kritis siswa melalui tes tulis. 
Tabel 5. Deskripsi Kemampuan Berpikir Kritis Siswa Setelah Perlakuan

\begin{tabular}{l|c|c}
\hline \multicolumn{1}{c|}{ Statistik } & Kelas Eksperimen & Kelas Kontrol \\
\hline Nilai terendah & 30 & 30 \\
\hline Nilai tertinggi & 100 & 100 \\
\hline Rata-rata & 70,67 & 62,67 \\
\hline Modus & 80 & 40 \\
\hline
\end{tabular}

Berdasarkan Tabel 5, kemampuan berpikir kritis siswa setelah perlakuan pada kelas eksperimen cenderung lebih tinggi daripada kelas kontrol, yaitu dengan rata-rata skor 70,67. Dengan demikian, kemampuan berpikir kritis siswa yang mengikuti pembelajaran praktik Project-Based Learning cenderung lebih tinggi daripada siswa yang mengikuti pembelajaran konvensional.

Project-Based Learning mampu membangkitkan kemampuan berpikir kritis siswa pada materi Segitiga dan Segiempat. Strategi ini mampu mendukung berbagai keuntungan yang didapat melalui pembelajaran berbasis proyek. Oleh karena itu, strategi ini menekankan ketuntasan yang dilakukan siswa pada praktik melalui alat peraga dengan kerja secara individu, pemberian penghargaan, maupun peran kolaboratif guru. Pembelajaran Project-Based Learning mampu membawa siswa aktif dan merasa memiliki tantangan intelektual yang lebih. Strategi ini mendorong siswa bertukar pikiran untuk menyelesaikan masalah, meningkatkan kepercayaan diri, serta melatih siswa menghargai perbedaan dan kekurangan siswa lain serta mendorong semangat belajar. Sebaliknya, pembelajaran konvensional yang diterapkan selama ini, belum mampu mendorong kemampuan berpikir kritis siswa secara optimal. Hal ini dapat terjadi karena strategi yang diterapkan pada pembelajaran dengan tuntutan kompetensi materi Segitiga dan Segiempat kurang sesuai.

Strategi pembelajaran Project-Based Learning diyakini lebih sesuai untuk diterapkan pada materi Segitiga dan Segiempat dibandingkan dengan strategi yang diterapkan selama ini, yaitu pembelajaran langsung. Alasannya Project-Based Learning memiliki karakteristik yang sesuai untuk pembelajaran materi tersebut. Sesuai hasil analisis data, dapat dilihat bahwa terdapat perbedaan kemampuan berpikir kritis antara siswa yang mengikuti pembelajaran dengan Project-Based Learning dengan siswa yang mengikuti pembelajaran langsung.

Analisis data hasil post-test kemampuan berpikir kreatif siswa dengan menggunakan program SPSS. Output dari hasil perhitungan SPSS adalah sebagai berikut : 
Tabel 6. Group Statistics

\begin{tabular}{c|c|c|c|c|c}
\hline & Kelompok & $\mathrm{N}$ & Mean & $\begin{array}{c}\text { Std. } \\
\text { Deviation }\end{array}$ & $\begin{array}{c}\text { Std. } \\
\text { Error } \\
\text { Mean }\end{array}$ \\
\hline $\begin{array}{c}\text { Kemampuan } \\
\text { Berpikir Kritis }\end{array}$ & Eksperimen & 30 & 70,6667 & 22,42741 & 4,09467 \\
\cline { 2 - 6 } & Kontrol & 30 & 62,6667 & 19,81524 & 3,61775 \\
\hline
\end{tabular}

Tabel 7. independent Samples Test

\begin{tabular}{|c|c|c|c|c|c|c|c|c|c|c|}
\hline & & \multicolumn{2}{|c|}{$\begin{array}{l}\text { Levene's Test } \\
\text { for Equality } \\
\text { of Variances }\end{array}$} & \multicolumn{7}{|c|}{ t-test for Equality of Means } \\
\hline & & \multirow[t]{2}{*}{$\mathrm{F}$} & \multirow[t]{2}{*}{ Sig. } & \multirow[t]{2}{*}{$\mathrm{t}$} & \multirow[t]{2}{*}{ df } & \multirow{2}{*}{ 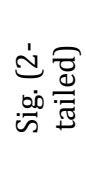 } & \multirow{2}{*}{ 莺 } & \multirow[t]{2}{*}{$\begin{array}{l}\text { Std. Error } \\
\text { Difference }\end{array}$} & \multicolumn{2}{|c|}{$\begin{array}{c}\text { 95\% Confidence } \\
\text { Interval of the } \\
\text { Difference }\end{array}$} \\
\hline & & & & & & & & & Lower & Upper \\
\hline 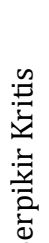 & 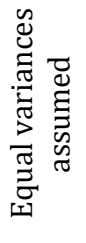 & 1,103 & 0,298 & 1,464 & 58 & 0,042 & 8 & 5,4639 & $-2,9372$ & 18,9372 \\
\hline 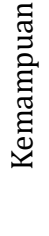 & 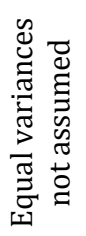 & & & 1,464 & 57,133 & 0,042 & 8 & 5,4639 & $-2,9408$ & 18,9408 \\
\hline
\end{tabular}

Berdasarkan output hasil perhitungan SPSS, terlihat bahwa nilai $t_{\text {hitung }}$ yang diperoleh sebesar 1,464 dengan sign. (2-tailed) 0,042. Karena nilai sign (2-tailed) 0,042<0,05, maka sesuai dasar pengambilan keputusan dalam uji Independent Sample T-Test dapat disimpulkan bahwa $\mathrm{H}_{0}$ ditolak. Jadi, ada pengaruh model pembelajaran Project-Based Learning berbasis alat peraga terhadap kemampuan berpikir kritis siswa kelas VII MTs Raudhatul Thalabah.

\section{Penutup}

\section{Simpulan}

Berdasarkan hasil penelitian dan pembahasan tersebut, dapat disimpulkan bahwa:

1. Terdapat pengaruh penerapan Project-Based Learning terhadap kemampuan berpikir kritis siswa dalam pembelajaran matematika dengan materi Segitiga dan Segiempat. Dan jika dibandingkan dengan 
pembelajaran langsung yang diterapkan selama ini di MTs Raudhatul Thalabah, Project-Based Learning pengaruhnya cenderung lebih besar.

2. Penerapan Project-Based Learning lebih mendorong kemampuan berpikir kritis siswa dibanding yang mengikuti pembelajaran langsung pada standar kompetensi tersebut.

Saran

Berdasarkan kesimpulan tersebut peneliti mengajukan saran agar dapat dijadikan bahan pertimbangan yaitu karena Penerapan Project-Based Learning lebih mendorong kemampuan berpikir kritis siswa dibanding yang mengikuti pembelajaran langsung pada standar kompetensi tersebut. Sekaligus Penelitian ini masih dapat dilanjutkan dengan mengkaji lebih dalam manfaat dari Penerapan Project-Based Learning.

\section{Daftar Pustaka}

Insyasiska, Dewi, Siti Zubaidah, and Herawati Susilo. "Pengaruh Project Based Learning Terhadap Motivasi Belajar, Kreativitas, Kemampuan Berpikir Kritis, Dan Kemampuan Kognitif Siswa Pada Pembelajaran Biologi.” Jurnal Pendidikan Biologi 7, no. 1 (April 5, 2017): 9-21.

Kurniawan, Muhammad Kharis, Natalia Rosa Keliat, Agna S. Krave, and Daud Ronal Hutagaol. "Penerapan Pembelajaran Aktif Berbasis Tugas Proyek untuk Meningkatkan Hasil Belajar IPA Siswa Kelas VII B SMP Kristen 2 Salatiga Tahun Pelajaran 2016/2017 Active Learning Application Based on Project Assignment in Improving Science Learning Results of Stu." Bioedukasi: Jurnal Pendidikan Biologi 10, no. 1 (February 15, 2017): 3342. https://doi.org/10.20961/bioedukasi-uns.v10i1.10140.

Maunah, Binti. Landasan Pendidikan. Yogyakarta: Teras, 2009.

Murti, Warda. "Pengaruh Pemberian Tugas Berbasis Proyek Terhadap Pengembangan Life Skill Dan Hasil Belajar Biologi Siswa Kelas VIII SMP." Jurnal Biotek 4, no. 1 (June 1, 2016): 21-32. https://doi.org/10.24252/jb.v4i1.1767.

"Peringkat Dan Capaian PISA Indonesia Mengalami Peningkatan.” Kementerian Pendidikan dan Kebudayaan, December 6, 2016. https://www.kemdikbud.go.id/main/blog/2016/12/peringkat-dan-capaianpisa-indonesia-mengalami-peningkatan. 